\title{
Erratum to: Intention to Use a Mobile-Based Information Technology Solution for Tuberculosis Treatment Monitoring - Applying a UTAUT Model
}

\author{
Ravi Seethamraju ${ }^{1}$ (D) Krishna Sundar Diatha ${ }^{2} \cdot$ Shashank Garg $^{2}$
}

Published online: 27 September 2017

(C) Springer Science+Business Media, LLC 2017

Erratum to: Inf Syst Front (2017)

https://doi.org/10.1007/s10796-017-9801-z

The original version of this article unfortunately contained missing acknowledgment. The information is given below:

\section{Acknowledgements}

This research was partially funded by the Australian Department of Foreign Affairs \& Trade Australia India Council and Digital Innovation Lab at the Indian Institute of Management Bangalore, India.”

The online version of the original article can be at https://doi.org/10.1007/ s10796-017-9801-z

Ravi Seethamraju

ravi.seethamraju@sydney.edu.au

1 The University of Sydney Business School, Sydney, NSW 2006, Australia

2 Indian Institute of Management Bangalore, Bangalore, India 